\title{
Potential utilization of satellite remote sensing for field-based agricultural studies
}

\author{
Keiji Jindo ${ }^{1^{*}}$ (D), Osamu Kozan ${ }^{2}$ D, Kohtaro Iseki ${ }^{3}$, Bernardo Maestrini ${ }^{1}$, Frits K. van Evert ${ }^{1}$, Yilma Wubengeda ${ }^{4}$, \\ Egidio Arai ${ }^{5}$, Yosio Edemir Shimabukuro ${ }^{5}$, Yoshito Sawada ${ }^{6}$ and Corné Kempenaar ${ }^{1}$
}

\begin{abstract}
Using satellite remote-sensing is a useful approach for agriculture to monitor plant and soil conditions and provide decision-making support to farmers. Recently, several types of tools and indices by the satellite remote-sensing have been developed for monitoring drought stress, changes in land uses, and crop-soil water relations. Although these techniques are powerful tools, especially in developing countries and regions where precise data of crop evaluation and yield statistics are not accessible, it is quite difficult for beginners to select the most suitable tool or index for their objectives. Major difficulties are in the specificity of the terminology, differences among the sensors (e.g., active vs. passive sensors), interpretation of imaginary data, and multidisciplinary topics. This work offers non-expert readers basic knowledge of remote-sensing use in agriculture, presenting advancements in the field and future insights. We review different sensors that are frequently used, such as optical sensors and synthetic aperture radar, as well as the following different purposes for using remote-sensing in agriculture: drought stress detection, monitoring land use in tropical regions (e.g., deforestation), and estimating water balance evapotranspiration in emerging and developing countries. Additionally, the integrated approach of remote-sensing data into the crop simulation model, which can provide a more holistic view of the plant and field status over cropping season, is described for the field-based studies.
\end{abstract}

Keywords: Satellite remote-sensing, Drought stress, Land-use map, Evapotranspiration, Deforestation, PALSAR

\section{Introduction}

Technologies of remote-sensing (RS) can be aircraftbased or satellite-based, enabling us to classify and detect objects to identify features and characteristics of the Earth system made from propagated signals such as electromagnetic radiation. There exist a wide range of different series of RS types from proximal RS to satellite RS. More than a thousand active satellites RS are orbiting earth these days, and many of them are for earth observation by satellite RS, which is equipped with one or more sensors and other materials. Information resources derived from satellite imageries are used

\footnotetext{
${ }^{*}$ Correspondence: keiji.jindo@wur.nl

${ }^{1}$ Agrosystems Research, Wageningen University \& Research, P.O. Box 16, 6700 AA Wageningen, The Netherlands

Full list of author information is available at the end of the article
}

extensively in the agriculture sector and support farmers' decision-making [1]. For example, a long-run remotely sensed product of the LANDSAT and MODIS are wellknown tools to monitor biomass in an agricultural field. At the same time, the tropical Rainfall Measuring Mission (TRMM), operated by the National Aeronautics and Space Administration, the USA (NASA), and The Japan Aerospace Exploration Agency (JAXA), provides precipitation data, which is often considered essential for field management [2]. Not only the rainfall, but also other variety of valuable information is available by RS technologies, including evapotranspiration, drought, soil condition and landscape [3-6].

The idea of applying satellite data in the agriculture sector has been sprout around in the 1960s and 1970s in the USA. The use of Landsat data in a project called Large Area Crop Inventory Experiment (LACIE) was 


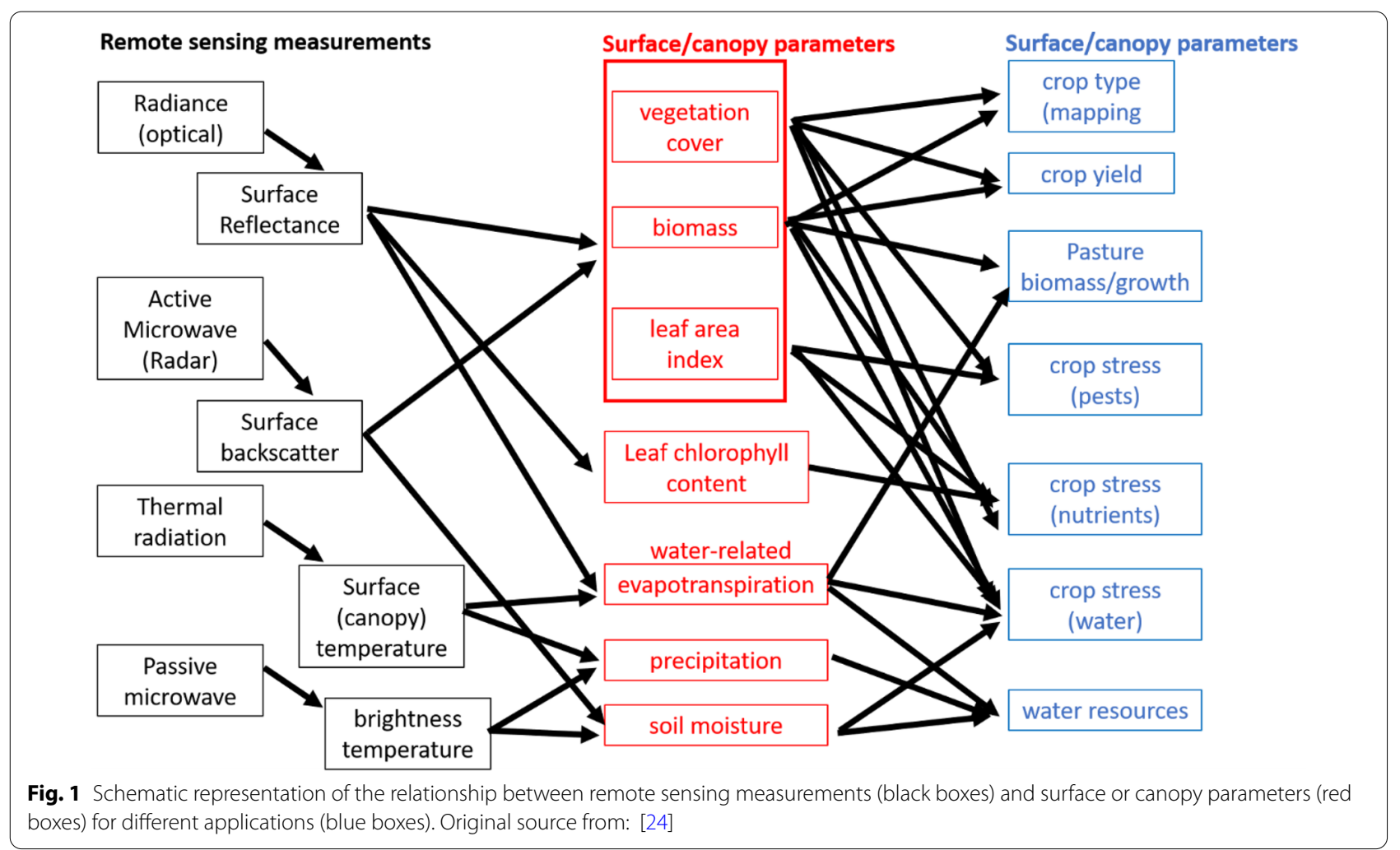

initiated in November 1974, which was 2 years after the first launch of NASA Earth Resources Technology Satellite (ERTS), later renamed as Landsat-1. The most popular social news was the estimation of winter wheat production in the Soviet Union in the 1970s by using LACIE [7]. In those days, simple indicators were developed to monitor the plant growths at a large scale, such as the Green Index Number (GIN), calculated by the percentage of pixels with greenness in a specific field $[8,9]$. For the late 1970 s and 1980s, more indicators have been developed and used along with other information such as meteorological data (e.g., precipitation and temperature). In the last 1980s, it was the first time to use the Normalized Difference Vegetation Index (NDVI), calculated by the wavelengths of near-infrared [10] and green, to monitor drought [11]. Then, using high-resolution satellite data, chlorophyll measurement was quantified [12], while evapotranspiration rate was quantified to monitor the energy/water balance for the irrigation system [13]. Given that crop properties, including above-biomass and leaf area index (LAI), can be estimated or monitored from space through optical vegetation indices (VI) as well as Synthetic Aperture Radar (SAR). As shown in Fig. 1, there exist different applications of satellite RS measurements in the agricultural domain. Nowadays, there exist more than 510 indicators of VIs, according to the https://www.index database.de.

As aforementioned, multiple satellite RS applications have been used in agriculture, such as creating a land cover and land use, monitoring plant growth and drought stress, and estimating water use efficiency. From a historical perspective, the use of RS data in agriculture has evolved over the past decades in its temporal and spatial resolution. This has expanded the usage of satellite RS data from the analysis carried out at the landscape level to the field level. A second major change occurred in the resolution of the optical sensors, with the possibility of measuring an increasing number of bands, including narrow bands. This has brought to the development of numerous vegetation indices and major improvements in the automatic detection of non-valid pixels such as clouds and shadows. A third big change was the usage of active sensors such as SAR, which provide measurements cloud-independent, resulting in an improved regularity of image availability, or satellite sun-induced fluorescence, which could provide valuable information on the efficiency of the photosynthetic process.

Although the great progress of RS technologies, most of its application to the agricultural domain has been restricted to special scientific studies, and few applications are made for farmers' practices. This is partly 
attributed that most cases of RS application to agriculture have been done only by the RS experts who are non-expert of field agronomy. To make the application of satellite RS more implementable on agricultural fields, rudimentary knowledge on RS utilization should be widely shared across the different disciplines concerning agriculture.

This paper illustrates the overview of the utilization of satellite RS in the agricultural domain. To achieve effective RS uses for agriculture, especially in the regions where the historical data or statistics for crop growth and yield are not fully available, reviews are done on several indices and tools for land use and land cover (LULC), drought detection, and water productivity. As an example of RS application to field-based studies, the application of the satellite RS into the crop growth model (CGM) is also described.

\section{Using satellite RS data for different purposes Land use and land cover}

It should be highlighted that satellite data can help create a land-use land cover (LULC) map. Several factors cause LULC changes: increasing pressure of food production due to the resource scarcity concerning population growth; changing market opportunities; abroad policy intervention; loss of adaptive capability and increased vulnerability; and changes in social organization and resource access attitudes. There is a need for accurate LULC maps to measure the impacts of LULC changes related to pasture expansion, agricultural intensification, urbanization, deforestation, and biodiversity loss. Satellite RS data and techniques are helpful for mapping LULC classes due to the synoptic view of large geographic regions and the relatively low costs. In the 1990s, the Advanced Very High-Resolution Radiometer (AVHRR) onboard the U.S. National Oceanic and Atmospheric Administration (NOAA) polar-orbiting meteorological satellite data were used to produce global land cover maps at spatial resolutions of $8 \mathrm{~km}$ [14] and $1.1 \mathrm{~km}$ [15]. In the 2000s, a global LULC map from 2000 was made available by the Global Land-Cover (GLC 2000) project [12], which used a dataset of 14 months of daily global images obtained by the SPOT-4 VEGETATION sensor.

Another example is the Moderate Resolution Imaging Spectroradiometer (MODIS) Collection 5 annual global land cover products generated at $500-\mathrm{m}$ spatial resolution (2001-2018) using supervised classifications of Terra and Aqua MODIS reflectance data [16]. Nowadays, the increasing availability of time series of satellite sensor images has become available. Their contribution to environmental management, biodiversity conservation, and land use planning emphasizes the need for specific approaches to properly deal with the unique characteristics and the amount of these datasets [17].

An example in Brazil is the digital platform of CANASAT, launched in 2007, to monitor the sugarcane fields where some of the farmers are still burning the sugarcane harvest, which triggers the climate change effect (Fig. 2). Using multispectral and multitemporal images, CANASAT can not only measures sugarcane field size, including three sub-classes (ratoon, expansion, and renovation), but also identify the type of harvesting (mechanization or manual harvesting by burning) $[18,19]$. The time-series approaches provide the patterns of LULC changes in time and incorporate seasonality and phenological cycles of vegetation into the analyses [20]. In that manner, satellite sensors with high-frequency acquisitions capability provide time series of observations that can improve land surface characterization at regional, national, and global scales. That is the case of the PROBA-V sensor, launched in 2013 as a continuity program of global land coverage provided by the SPOT VEGETATION [21]. The PROBA$\mathrm{V}$ datasets are produced every 2 days at $300 \mathrm{~m}$ spatial resolution and every 5 days at $100 \mathrm{~m}$ spatial resolution (see Fig. 3). The images are available in surface reflectance format to be transformed as vegetation indices or fraction images derived from Linear Spectral Mixing Model (LSMM). The PROBA-V $100 \mathrm{~m}$ data have been used for LULC classification in African countries [22], crop area mapping of globally spread agricultural areas in Belgium, Russia, Ukraine, and Brazil [23], and crop mapping of Mato Grosso state, Brazil [24] among other applications.

The most common parameters derived from satellite RS are the vegetative indices (VI), and the typical ones are NDVI, EVI, and SAVI. Generally, the coarse/medium satellite RS data (LANDSAT, ASAR, MODIS) are the data resources for those Vis, which can be scaled up to the regional level. And these resources are long-run products that make users overlook the trends of production from the past to the present. This feature enables to the creation of maps of land use land change in a certain period [25]. It is recently reported that GCVI performs better for estimating canopy greenness than traditional indexes (NDVI and EVI), given that the green wavelength is more responsible than red reflectance [26].

\section{Drought indices for the detection of target populations of the environment}

Increases in agricultural drought are a serious issue on global food production, particularly in the semi-arid and arid regions where the precipitation goes more variable at the same time with a decrease in mean annual rainfall [27] and the drought events simultaneously consequently accelerate soil degradation [28]. The development of drought-tolerant crop variety is the most important and 


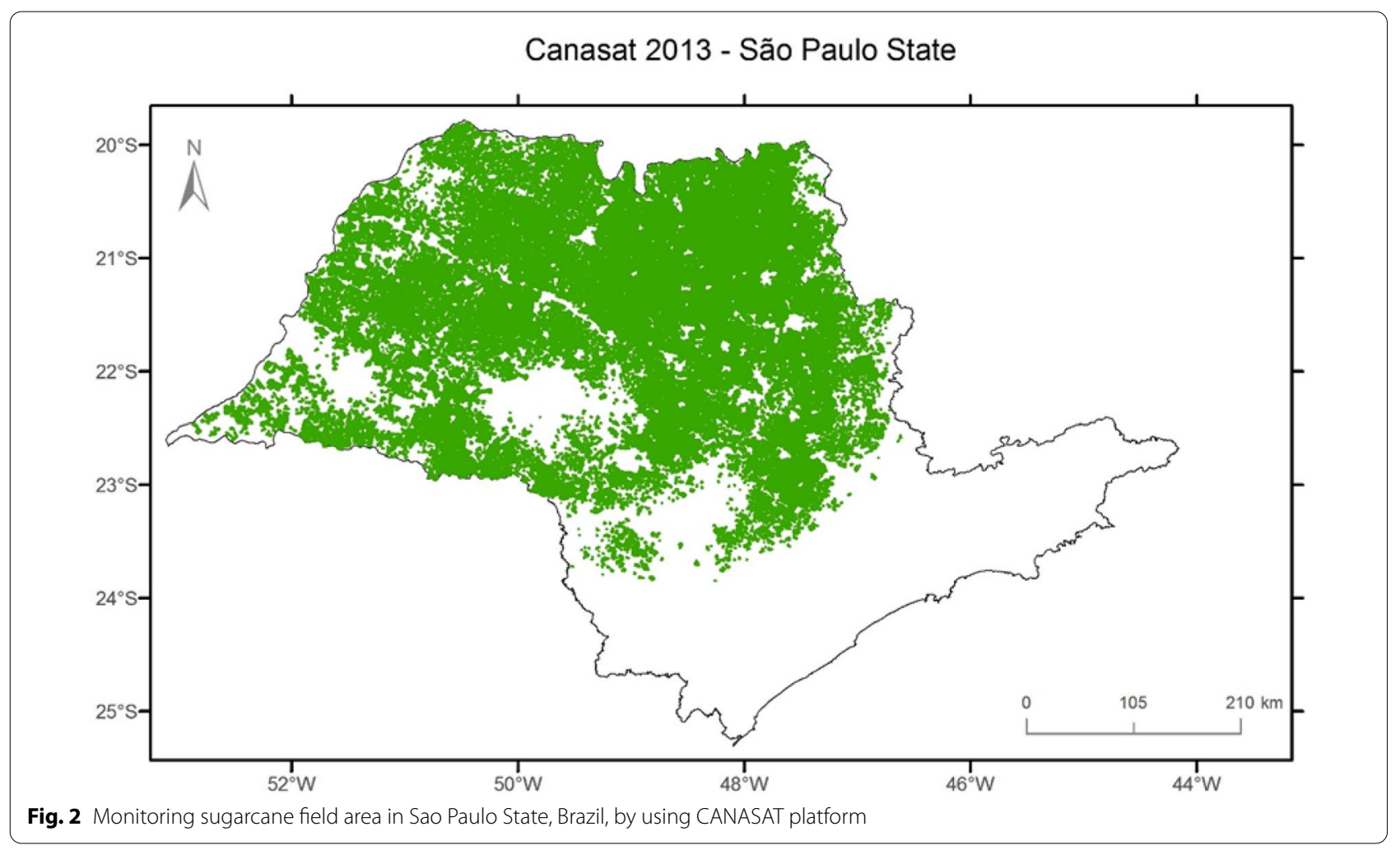

feasible solution [29]. The target population of environments (TPE) is a major concept of environmental classification to be targeted in drought-tolerant breeding. This is based on the notion that the genotype-by-environment interactions cause non-linear plant responses to the series of environments [30, 31]. As for drought stress, the tolerant genotypes or species vary based on different drought circumstances associated with frequency, intensity, and duration of plant water scarcity [32, 33]. In addition, also soil types and farmer's practices should account for the TPE. For example, plants grown on soils with high water permeability and low fertility are more vulnerable to drought stress [34]. Farmers' practices such as irrigation and plowing also affect the intensity of drought stress [35].

Although elucidating a TPE of the target region is critically important to determine breeding objectives for drought tolerance, it has not been easy because of a lack of reliable data on historical drought events and its patterns. Especially for drylands in Africa, the meteorological records and crop statistics are scarce and sometimes not available. Satellite RS can detect the occurrence of drought stress spatially and temporally, and thus it is thought to be a powerful tool to elucidate TPEs across the region. So far, drought indices and its application to agricultural fields have been well studied and summarized in previous studies [36, 37]. However, little consideration has been made for the application of satellite RS to crop breeding. This section focused on applying satellite RSderived drought indices to detect TPEs and provide the information needed for drought-tolerant breeding.

As for drought stress in agricultural fields, TPE could be defined as the historical pattern of drought occurrence characterized by the severity, frequency, and duration of plant water scarcity. As a method without satellite RS data, the climate-based indices such as standardized precipitation index (SPI) and standardized precipitation evapotranspiration index (SPEI) have been used to identify such historical drought events [38]. However, plant drought stress cannot be defined only by precipitation. Thus climate-based drought indices are restricted to an agricultural area with uniform soil type, same crop species, and same agricultural management. On the other hand, because the application of satellite RS enables us to evaluate the spectral reflectance of the ground surface covered by crop canopy, it reflects the direct feature of crop growth and physiological status, including the effects of soil types and crop species. Therefore, satellite RS-derived drought indices are suitable to know the crop status for wide ranges of agricultural areas, including various crop species, multiple soil types, and different farmer's practices.

Normalized difference vegetation index (NDVI) and land surface temperature (LST) are widely used for 


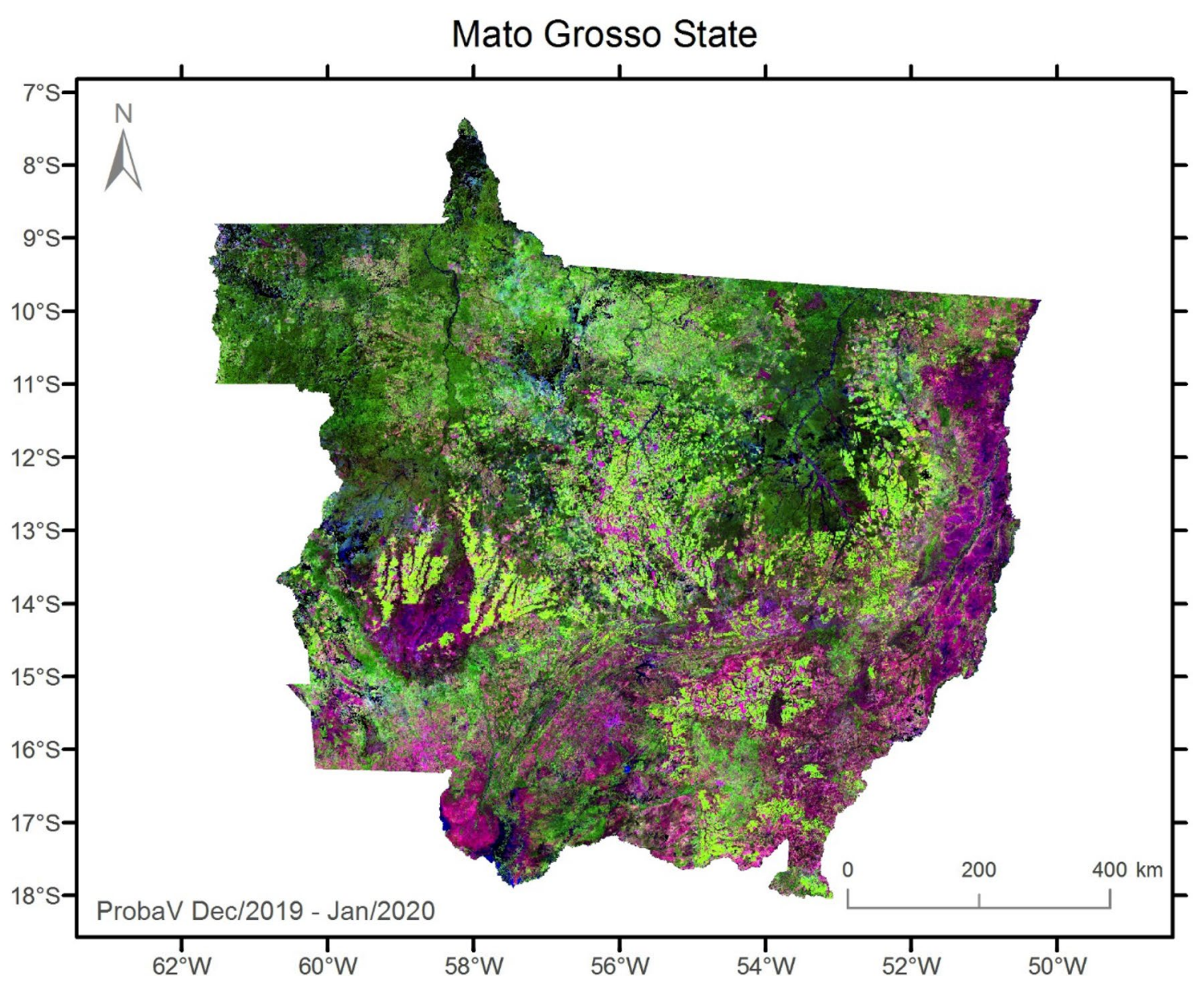

Fig. 3 The land-use map using PROBA-V, including forests (dark green), agricultural area (light green/yellow areas) and bared land (purple/ magenta)

satellite RS-derived drought indices, and both are the primary products of spectral reflectance [39]. The vegetation condition index (VCI; Eq. 1) represents the relative value of NDVI to the whole fluctuation range of the time records [40]:

$$
\mathrm{VCI}=\frac{\mathrm{NDVI}_{\mathrm{t}}-\mathrm{NDVI}_{\mathrm{t} \text { min }}}{\mathrm{NDVI}_{\mathrm{t} \cdot \max }-\mathrm{NDVI}_{\mathrm{t} \text { min }}} .
$$

NDVIt.max and NDVIt.min are the maximum and minimum values within the time records of NDVI for the period $t$ (Fig. 4), where NDVIt is the value at a period $t$ in a year. The lower VCI represents the lower vegetation mass than its potential, meaning severer stress. Sahoo et al. [41] detected agricultural drought events from a historical transition of $\mathrm{VCI}$ and showed that the detected drought event corresponded to SPI. On the other hand, they also reported that VCI was mainly related to severe drought, but failed to see moderate drought. This might be because there is time lag between drought onset and the start of vegetation/NDVI decrease under moderate drought conditions [42]. Another problem is that the decline in NDVI is not always caused by drought stress. For example, disease and insect damage and delay in sowing time also decrease VCI. Therefore, VCI needs corroborative use with other indexes such as soil moisture data or yield statistics [43].

The temperature condition index (TCI; Eq. 2) is similar to VCI but uses LST instead of NDVI [44]. This index is used based on the assumption that LST increases under drought conditions due to decreased latent heat flux from crop canopy and bare soil. Because the stomatal closure and reduction of leaf transpiration are the initial plant response to drought stress [45], the increase in LST occurs much prior to reducing plant biomass. Therefore, compared to NDVI, LST is sensitive to vegetation water status, and there is little time lag, and thus real-time drought monitoring is possible: 


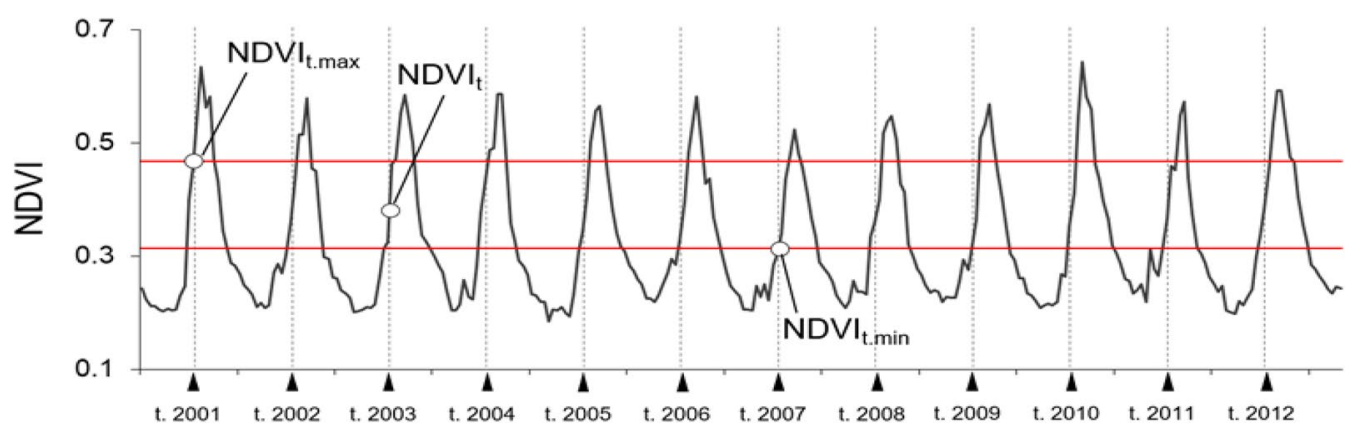

Fig. 4. Historical changes of NDVI in the West Africa region during 2001-2012

$$
\mathrm{TCI}=\frac{\left(\mathrm{LST}_{\mathrm{t} \text { max }}-\mathrm{LST}_{\mathrm{t}}\right)}{\left(\mathrm{LST}_{\mathrm{t} . \max }-\mathrm{LST}_{\mathrm{t} \text { min }}\right)}
$$

where $\mathrm{LST}_{\mathrm{t}}$ is the value at a period $\mathrm{t}$ in a year. $\mathrm{LST}_{\mathrm{t} \text { max }}$ and $\mathrm{LST}_{\text {t.min }}$ are the maximum and minimum values within the time records of LST for the period t. The lower TCI represents severer drought stress. TCI usually has been used as a complementary indicator of VCI for drought detection [46]. Seiler et al. [47] reported that the combined use of these indices explained more than $70 \%$ of maize yield variation, and it was well aligned with precipitation patterns. However, actual drought intensity still differs even for pixels with the same TCI values due to different vegetation sizes. For example, TCI values are possibly the same for pixels of drought surface with larger vegetation and wet surface with small vegetation.

The VCI and TCI address the historically abnormal drought events at a target area, although careful consideration with other meteorological data records and landuse information is needed for their application. Kukunuri et al. [48] reported that the combined use of VCI and TCI could successfully detect the historical drought without requiring a priori information. However, those values cannot be compared with those in other areas with different environments because the absolute values of NDVI and LST are largely affected by the local settings such as soil fertility, air temperature, and solar radiation. Therefore, VCI and TCI are available to define the TPEs for relatively small areas with similar basal environments.

On the other hand, spatial comparison of the index value is possible for vegetation and temperature condition index (VTCI; [49]) and temperature-vegetation dryness index (TVDI; [50]). Both are similar indices obtained from scatterplots of NDVI and LST for an imaged area (Fig. 5):

$$
\mathrm{VTCI}=\frac{\mathrm{LST}_{\mathrm{NDVIi.max}}-\mathrm{LST}_{\mathrm{NDVIi}}}{\mathrm{LST}_{\mathrm{NDVIi.max}}-\mathrm{LST}_{\mathrm{NDVIi.min}}},
$$

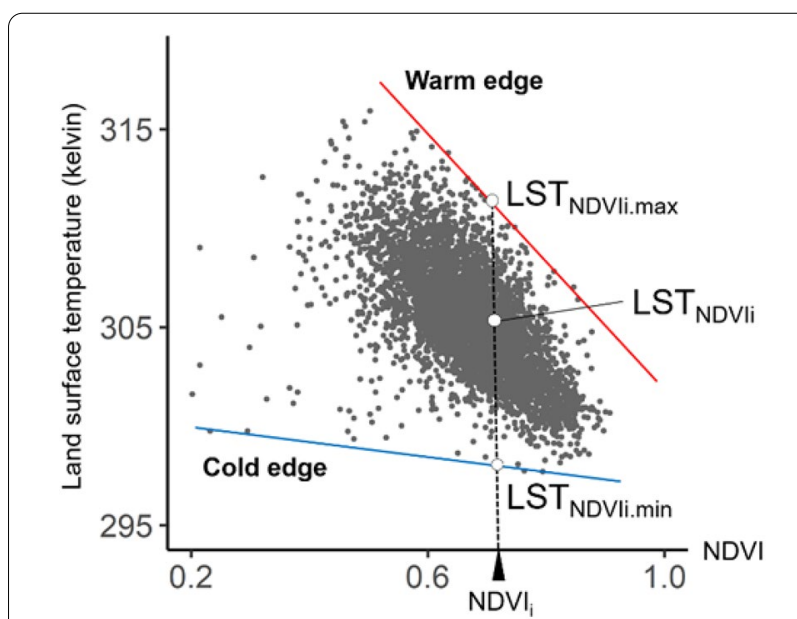

Fig. 5 Determination of parameters for VTCI and TVDI from scatterplot of NDVI and LST. The red and blue lines represent the warm and cold edges drawn from pixels with maximum and minimum LST values at the given NDVI. NDVI and LST were obtained from $T$

$$
\mathrm{TVDI}=\frac{\mathrm{LST}_{\mathrm{NDVIi}}-\mathrm{LST}_{\mathrm{NDVIi.min}}}{\mathrm{LST}_{\mathrm{NDVIi.max}}-\mathrm{LST}_{\mathrm{NDVIi.min}}}
$$

NDVIi is NDVI of the target area at a given time, and LSTNDVIi is the LST value of the same pixel. $\mathrm{LST}_{\mathrm{NDVIi}}$ $\max _{\text {max }}$ and $\mathrm{LST}_{\text {NDVIi.min }}$ are maximum and minimum LSTs of pixels where NDVI value is the same as NDVIi. These maximum and minimum values are generally calculated from linear regression between LST and the warm or cold edges in the scatterplot represented by the red and blue lines in Fig. 5 [51]. The lower VTCI and higher TVDI represent severer drought stress. These indices well address the problem of TCI, which does not consider the effect of vegetation size on the LST. Because VTCI and TVDI are calculated from LSTs of pixels with the same NDVI, they can successfully detect the spatial distribution of drought stress even for an imaged area 
including vegetation heterogeneity. However, users need to pay attention that the warm and cold edges are taken from NDVI and LST of multiple crop surfaces, and the actual intensity of drought stress exposed is different for crop species, even for the same TVDI values.

Difficulties with using VTCI and TVDI in the TPE detection are that the relationship between LST and NDVI varies over different time points because of the daily or seasonal variability in background environments such as air temperature and solar radiation including the effect of solar illumination angle. This indicates that the warm and cold edges are different for each of the images in the time series, and thus, it is hard to compare the drought intensity among the images of different days. The temperature vegetation precipitation dryness index (TVPDI) is the combined index between TVDI and precipitation data provided from the tropical rainfall measuring mission (TRMM) [52]. The precipitation data were used to normalize the basal environment of each NDVILST space taken from different seasons to detect the spatiotemporal drought status. However, given that environmental factors, especially air temperature and solar radiation, largely affect LST, the NDVI-LST space is hard to apply for large areas with different climate zones such as continental or sub-continental bases. Another difficulty is that LST data are rarely available during the wet season due to the effect of the cloud, which deeply covers the imaged area. This drawback could be partly overcome by the microwave temperature vegetation index (MTVDI) calculated by microwave sensors instead of the basic optical sensors based on that the microwave sensors are less affected by atmospheric conditions [53].

The above-mentioned drought indices are viable tools to detect drought occurrence and have been improved by additional information from other sensors. However, there are still restrictions for the long-term spatiotemporally drought detections in agricultural fields to understand the TPE. First, most indices can catch either one of the historical drought events of a pixel (VCI and TCI) or spatial distribution of drought at a given short period (VTCI and TVDI). Second, even the improved indices with multi-sensors detecting spatiotemporal drought events (TVPDI) cannot apply fully for long-term analysis because of the limitation of long past data of additional sensors. Third, plant stomatal response regulating the transpiration rate and the LST to its water status is different for crop species [54]. Therefore, the relationship between the LST and drought intensity is diverse depending on crop species, and thus the LST should be evaluated together with other physiological indices such as photosynthesis (PRI; [55]), chlorophyll fluorescence (SIF; [56]), and chlorophyll content (MTCI; [57]).
Normalized difference water index (NDWI) is one of the comprehensive drought indices available for historical and spatial drought detection [58]. This index represents the liquid water amount inside the vegetation. This is a primary index calculated from the following equation, and the lower values represent the occurrence of drought stress:

$$
\mathrm{NDWI}=\frac{\mathrm{R}_{\mathrm{NIR}}-\mathrm{R}_{\mathrm{MIR}}}{\mathrm{R}_{\mathrm{NIR}}+\mathrm{R}_{\mathrm{MIR}}}
$$

where RNIR and RMIR are the reflectances of near-infrared and midinfrared, which corresponds to band 2 (841$876 \mathrm{~nm})$ and band $6(1628-1652 \mathrm{~nm})$ for MODIS, band $4(760-900 \mathrm{~nm})$, and band5 $(1550-1750 \mathrm{~nm})$ for Landsat $\mathrm{EM}$ and ETM +, and band $5(845-885 \mathrm{~nm})$ and band6 $(1560-1660 \mathrm{~nm})$ for Landsat OLI, respectively. Jackson et al. [59] reported that changes in vegetation water content during crop growth periods were better explained by the regression model using NDWI than NDVI. On the other hand, because the regression model highly depends on the plant architecture, NDWI is not available to diverse terrain and climate area due to land cover heterogeneity and soil type [60].

To overcome the drawback of the NDWI application, a normalized difference drought index (NDDI; Eq. 6) was developed [61]. NDDI focused on the notion that the difference between NDVI and NDWI increases with decreasing vegetation water content:

$$
\mathrm{NDDI}=\frac{\mathrm{NDVI}-\mathrm{NDWI}}{\mathrm{NDVI}+\mathrm{NDWI}} .
$$

The higher values of NDDI indicate lower vegetation water percentage and the occurrence of drought stress. Due to the involvement of NDVI as a parameter, the effects of vegetation size and soil type are incorporated in this index. Thus, it is widely available to multiple cropping areas and is more sensitive to drought than the single use of NDVI or NDWI. Orimoloye et al. [62] applied NDDI to assess historical and spatial drought severity and found the specific areas and periods of drought occurrence. Because the NDDI represents a temporal plant water status and is little affected by meteorological conditions other than drought, it seems to be suitable to use for the TPE detection, although further studies are needed to clarify the relationship between NDDI and physiological factors related to plant drought responses.

\section{Synthetic aperture radar (SAR) sensor}

Another type of satellite RS data used in agriculture is the synthetic aperture radar (SAR) system. Unlike the optical sensor, microwave electromagnetic radiation is a key component in an active SAR system transmitted to 
objectives and received the reflected echoes on the land surfaces. This system enables to determine the structure of each object on the surface. SAR uses the motion of the radar antenna over a target region to provide finer spatial resolution than conventional beam-scanning radars. Since SAR measures the distance between terrain features and the antenna, geometric distortions such as foreshortening, layover and shadow occur in SAR image [63]. The returned signal which has been recorded by the sensor is usually expressed as backscattering coefficient $(\sigma 0)$, which is dependent on soil moisture content [64], but is also affected by surface characteristics, radar angle and wavelength and so on [65]. Surface characteristics, such as roughness and vegetation cover, have a significant influence on the backscattering coefficient $(\sigma 0)$; thus, many theoretical, empirical and semi-empirical models have been developed to relate the SAR backscatter coefficient to soil moisture [66, 67].

An attractive trait of the SAR system is the advantage of a long wavelength, which can penetrate through the cloud. At the same time, the optical sensors have a reliance on sunlight, which limits proper data acquisition. Especially, this beneficial advantage can be helpful in frequently clouded areas in tropical regions. Another feature of SAR is that full polarimetric SAR comprises four combinations of polarization $(\mathrm{HH}, \mathrm{HV}, \mathrm{VH}, \mathrm{VV})$ that can monitor different phenology stages of plant growth, such as plant height [68] and biomass [69]. The sensitivity of the SAR data to the soil status enables monitoring field conditions and management on the ground [70] and drenching with water in the paddy rice area [71]. This trait also provides an empirical estimation of soil moisture content [72, 73]. L-band SAR yields good results under various canopy types because it has a higher penetration power through vegetation canopy to reach the soil surface [74]. Compared with other bands, L-band SAR has more sensitivity to soil moisture change due to the larger emission [75-77] distorted measurement of soil moisture probably occurs in C-band because of high sensitivity to vegetation cover $[78,79]$. However, L-band has difficulty identifying certain crop types, given that its wavelength is $1.2 \mathrm{GHz}$, which penetrates some plants with a height between 6 and $10 \mathrm{~cm}$.

Furthermore, spatial high-resolution $(<10 \mathrm{~m})$ of existing SAR data resources such as SENTINEL and PALSAR is a suitable tool for detecting variation in crop growth and soil property within a field and monitoring smallholder farming. Perennial crops are in the tropical region an easily detectable crop for identification and estimation of biophysical properties such as cashew [80], rubber [81, 82], almond [83], and palm [84, 85]. Creating a land-use map covering different crop locations using SAR data is an attractive approach to understanding and monitoring the field management at a community level (Fig. 6). Mizuno et al. [86] exhibit the land-use map in Tanjung Leban village, Indonesia, using five imagery scenes from Fine Beam Duam (FBD)-ALOS-PALSAR. The map was created based on a ratio of two backscatters of $\mathrm{HH}$ and $\mathrm{HV}$ in dry and rainy seasons, which were later processed by interferometry. The underlying key advantage was the combination of the strong points of $\mathrm{HH}$ and $\mathrm{HV}$ measurements of L-band. While $\mathrm{HH}$ has a sensitivity of distinguishing the state of the ground surface penetrating plant canopy, $\mathrm{HV}$ is more sensitive to above-biomass [80, 87].

Another contribution of the SAR data to the agriculture sector can be seen as a component for creating a digital elevation map (DEM). The DEM data of The Shuttle Radar Topography Mission (SRTM) is extensively used worldwide to estimate elevation, slope, and watershed. Other DEM data are also applied in agriculture such as TanDEM, Advanced Spaceborne Thermal Emission, and Reflection (ASTER)-Global Digital Elevation Model (GDEM), ALOS world 3D-30m (AW3D30), TerraSAR-X add-on for Digital Elevation Measurement (TanDEMXDEM), Advanced Spaceborne Thermal Emission and Reflection (ASTER)-Global Digital Elevation Model (GDEM).

The Copernicus program's policy for free and fully open access has boosted remarkably the application of the SENTINEL in agriculture. It is noteworthy to outline some constraints of the SAR data. The limited frequent visits are a major constraint to monitor the phenological development and field condition. Secondly, the future study is required to improve the high accuracy of soil moisture measurement. When it comes to creating a retrieval soil moisture measurement by using multi-layers, the soil depth contribution to the L-band radiometer signal $(\sim 5 \mathrm{~cm})$ is different from that of the C-band SAR backscatter signal $(\sim 2 \mathrm{~cm})[87,88]$. The high-resolution data often suffer from the saturation of values in highresolution satellite data [30].

One future study can be the combined application between SAR and other sensor technologies. For example, combining SAR and hyperspectral imagery (e.g., Rapideye) can create more accurate land cover maps where different crop types are cultivated [89]. Even cocoa crops, which preferably grow under a shadow, can be delineated with this combination in an agroforest system [90].

\section{Water productivity in agriculture based on surface energy balance model \\ Evapotranspiration and water scarcity}

The water scarcity problem in the agricultural field can be addressed by increasing the amount of crop yield per specific amount of water used. Estimation of actual 


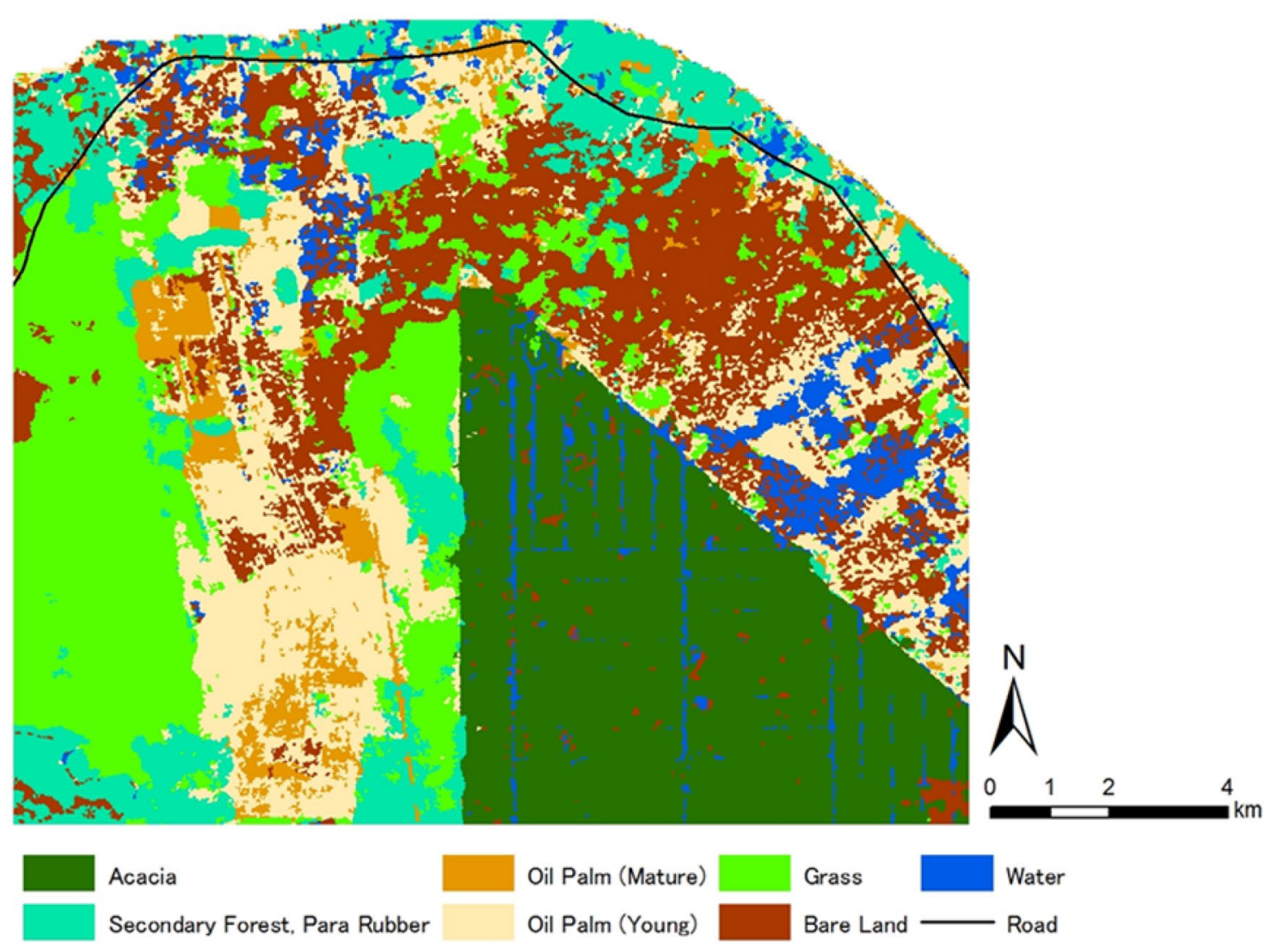

Fig. 6 Land-use map in Indonesia by using SAR data (source: [60])

evapotranspiration (ECa) is the only way to express the actual amount of water consumed. Therefore, measuring actual evapotranspiration plays a more significant role in coping up with the water scarcity problem. Seiler and Moene [91] summarized the major methods to estimate the actual evapotranspiration as "lysimeter, flux towers, crop coefficient consideration, and satellite RS algorithms". The central concept of actual evapotranspiration is to assess the actual amount of water used by the crop influenced by different factors. Lysimeter and flux towers estimate actual evapotranspiration per point, and it requires intensive data collection [91]. Crop coefficient consideration is not a practical way to estimate actual evapotranspiration due to the limited availability of a confidential coefficient value for the "natural vegetation" [91].

Surface energy balance is one of the satellite RS approaches to estimate spatial and temporal ECa of crop growth. Bastiaanssen et al. [92] created a surface energy balance model for land (SEBAL) to assess the water productivity using actual evapotranspiration and biomass of a crop. The main inputs of SEBAL models are satellite images (Landsat), DEM, land use, and weather data (Fig. 7). These inputs are used to directly estimates albedo, vegetation index, and surface temperature to be used as input on the final stage to calculate from soil heat flux, sensible heat flux, and net radiation (see Fig. 7) [92]. SEBAL has been used worldwide to carry out a spatial variation of water productivity, yield, and ETa for different crops under the different agro-ecological zone. SEBAL proved the Al-Khazir Gomal Basin, Iraq, by providing spatially variable ETa and recommending the results for "monitoring irrigation water needs" [93]. Understanding SEBAL measured ECa, biomass, and water productivity of a field or a basin supports the assessment of irrigation field's water management, decision-making on designing and constructing of irrigation infrastructures, and equitable water allocation [13, 93, 94]. And in the end, we can estimate the biomass production, that is, a function of light use efficiency (LUE), absorbed photosynthetically active radiation (APAR), change in time $(\Delta t)$, and environmental stress factors accumulated above-ground biomass for a certain period is expressed as follows: 


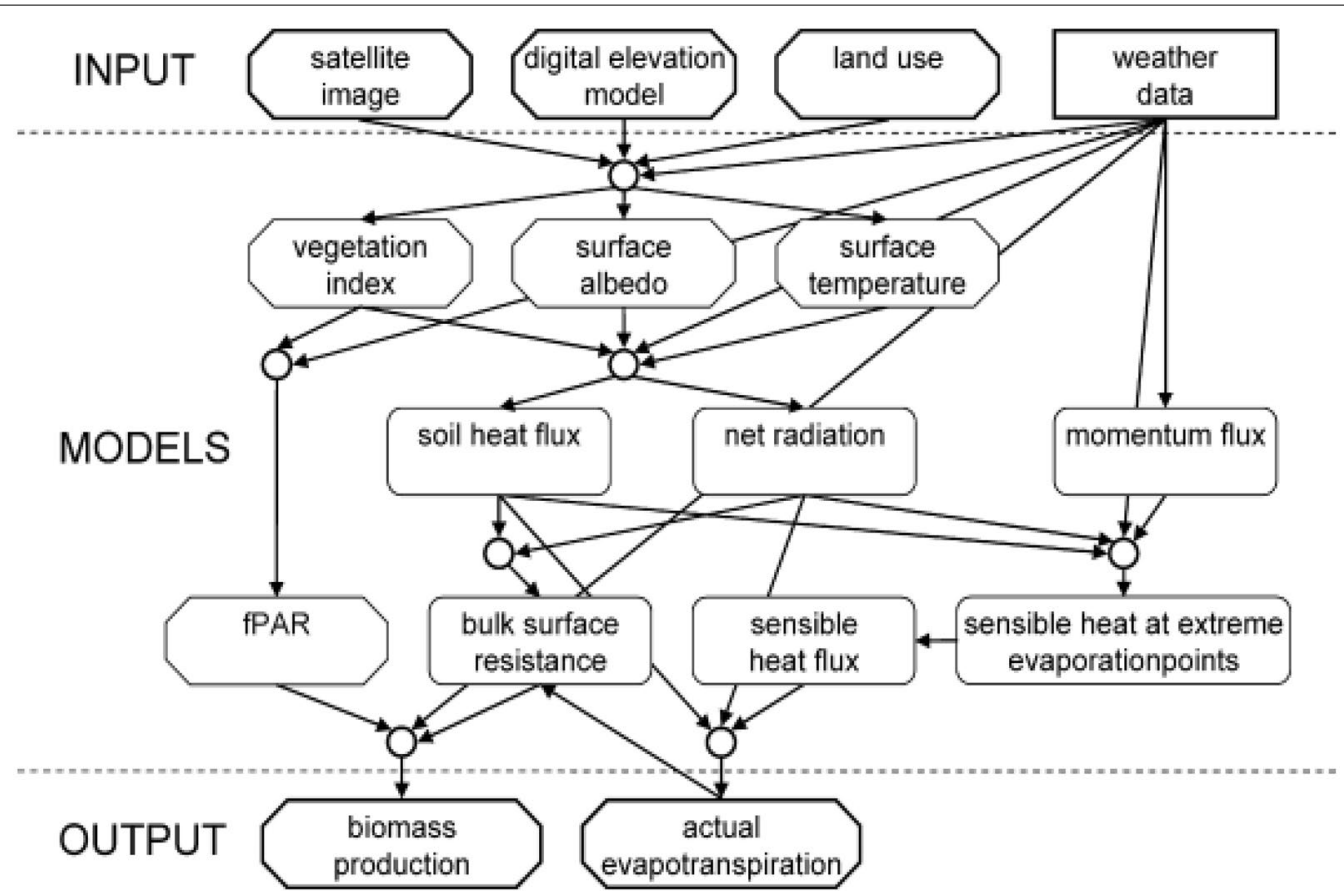

Fig. 7 Summarized scheme of SEBAL model. Source: [95]

$$
\text { Biomass }=\operatorname{LUE} \sum_{0}^{\mathrm{t}} \mathrm{APAR} \Delta \mathrm{t} .
$$

All of the PAR cannot be absorbed by the canopy due to reflecting and transmitting the nature of the leaves. Therefore, only a fraction of PAR will be absorbed by the chlorophyll, called "Absorbed photosynthetically activate radiation (APAR) as follows:

$$
\text { APAR }=-0.161+1.257(\mathrm{NDVI}) \times \text { PAR }
$$

\section{SEBAL water productivity (WP) for water-related \\ decision-making}

Much research used the spatial variation of WP, yield, and ETa to identify the gaps and to recommend the measures [13, 96, 97]. Water managers and irrigation engineers are always interested in having an overview of how water productivity is distributed over a basin or irrigation system level to help make decisions about improving water management [13]. It is always possible to find water productivity from a field experiment for a single location and crop growth. Having different crops and bigger areas makes it difficult to have information on a larger scale [13]. Since SEBAL is also used to assess the variation of WP under one system, its map provides information where water productivity is low, so water resources and irrigation managers could plan a better water distribution [13].
Knowledge of spatial variability of WP, yield, and actual evapotranspiration will make decision-making effective. The use of SEBAL for African vineyards shows how water productivity and yield spatial distribution with the distribution of the farmer interest, "farming strategies" of the farmers are seen in SEBAL WP, yield, and ETa variation. Bashir et al. [98] assessed the ETa value of sorghum fields in 18 different farming groups in Sudan. A recommendation was made for the farmers and irrigation engineers to understand how much water needs to be delivered to specific farms and increase water productivity for each farm [98]. In contrast, spatial distribution in Indus and Ganges river basins in India showed a significant spatial variation of rice yield and variation of water productivity for both wheat and rice crops, and the cause of the variation and scope of improvement were spatially analyzed [96]. Water fluxes in paddy rice area in India by using SEBAL covering evapotranspiration variability was created to make heterogeneous cropping calendars for decision support system at regional level [99].

Monitoring water resource and biomass development is a crucial tool for farming systems in semi-arid and arid regions, and SEBAL was used again to assess the spatial variation of wheat yield, water productivity, and evapotranspiration in different countries such as Mexico, India, and Egypt [13]. ETa spatial variation study carried out in the Hetao irrigation district, Northern China; ETa shows a significant variation in the study area, giving a higher 
ETa in arable lands but gave low ETa in sandy and desert land [100]. They concluded that this model could be well implemented in the Hetao area, with a relative error of $14.6 \%$ at field scale on $5-7$ days basis and $5.6 \%$ at regional scale on an annual basis.

\section{Critical points of SEBAL}

With the availability of free and high-resolution satellite images, it will be possible to assess more precisely the spatial variability of WP, yield, and ETa for smallholder farmers having a limited field size. Recently, a new article regarding scaling-up to $30-\mathrm{m}$ evapotranspiration rate in several countries has been published using GGE [101]. However, even though SEBAL is has been proved to estimate ETa, biomass, and WP effectively in many parts of the world, few main points need to be carefully considered. (1) The validation of SEBAL ETa with ground data is always recommended for different agroecology; (2) pySEBAL is a new version of the SEBAL scripting tool that automates the selection of hot and cold pixels. This model reduces the risk of the wrong choice of hot and cold pixels and cut-off the image processing time. Even though SEBAL has been validated in different areas, the automated selection of hot and cold pixel SEBAL needs to be validated with ground measured data for different agro-climatology. (3) Biomass accumulation calculation with absorbed photosynthetically active radiation considers environmental stress factors such as moisture, heat, and vapor pressure stress. All the environmental factor stress needs to be validated and adjusted for the target.

\section{Development of evapotranspiration models after SEBAL models}

Over two decades, a large number of new methods of evapotranspiration have been reported since the establishment of the SEBAL model [92] as the starting point. Apart from the surface energy balance models (SEB), SEBAL is the major representative. Other methods have been developed based on different methodologies, such as the Penman-Monteith method, Priestley-Taylor methods, and surface temperature-vegetation index (Ts-VI) space method [102]. These methods are contrasting approaches in terms of the degree of the complexity, type of the variables derived from satellite RS, and the underpinning process. Another trend is the integrated approach with other related subject for other purposes such as water balance method for the application at basin scale as well as water-carbon linkage methods [103] with the quantification of global gross primary productivity (GPP) together with evapotranspiration [104].

With the large development of remote RS technologies, those methods have been established. However, some pitfalls exist in this development process, according to Zhang et al. [102]. Firstly, there is little information on the research focused on identifying the uncertainty and minimizing its propagation. Secondly, the integrated approach using different evaporation methods can be a valuable asset to overcome the limitations. Thirdly, it requires further development of the remote RS technologies in terms of resolution and resolution.

\section{A recent approach for the evapotranspiration measurement using SEBAL-based models}

It should be noteworthy that the new approaches in recent years remarkably contribute to the improvement of the evapotranspiration measurement which the above-mentioned difficulties have been partly resolved. Especially, the latest research trends of monitoring water management with a higher resolution map based on the evapotranspiration rate have gradually increased. The common underpinning structure is the synergetic use between high-resolution data (e.g., SENTINEL) and other satellite medium resolution RS (MODIS and/or Landsat). For example, "Agriwater", an R programming package, was created for spatial modeling of energy balance and actual evapotranspiration in Brazil using SENTINEL, Landsat, and MODIS [105]. In contrast, the co-application of the enhanced SEBAL model, called "SEBAl" and SENTINEL-2 and MODIS LST, enables monitoring monthly $10-\mathrm{m}$ evapotranspiration rates in Lebanon [106]. The high resolution (10m) mapping for spatial variability in evapotranspiration, biomass and yield Tanzania has been developed based on SEBAL, Sentinel-2, and Landsat [107]. Also, another approach using machine learning solely for MODIS data should be highlighted to improve the actual evapotranspiration measurement in Brazil [108]. SEBALIGEE, a web-based model in Google Earth Engine, is also developed for the 30-m evapotranspiration rates for a wide range of crop types in different countries [101]. To minimize the gap between the simulation and the ground-truth data, the integration of soil moisture measurement using SENTINEL into SEBAL model has been developed [109].

\section{Assimilation of satellite RS data into crop growth model}

Crop simulation models (CSM), generally structured based on system analysis of plant phenology over different stages of plant development, are a useful tool to forecast crop growth and yield prediction on in-field scale up to regional or country level. The origin of many CSMs was sprouted in the 1960s by pioneer scientists such as C.T. de Wit, Monteith [110, 111], and Duncan et al. [112]. Their main focus was the canopy assimilation related to light interception and canopy architecture. As time went by, the development of whole crop models was gradually 
carried out in the 1970s $[113,114]$. One of the main traits of CSMs is the degree of complexity which largely varies depending on the objective of each model usage and its design. Basically, there are two different main categories of CSMs. Firstly, there is a group of statistical models, often named "empirical models" and "correlative models". And these models are normally expressed with a regression equation. Relatively, less volume of the dataset is required compared to the second group of CSMs. As a sub-category of statistical models, there are three main types referred to as time-series, panel, and cross-sectional approaches. Secondly, we have dynamic models, frequently called "process-based models", and these are created based on the different equations for each different phenological stage of crop development.

Given that these models employ functions that estimate the proxy of the developing process of plant and soil being for a certain time, it requires plenty of input parameters to run the models, compared to the statistical model. The advantage of this model is the availability of exploring future scenarios under different field management and different field conditions. As an example, the design of DynAcof model based on the for agroforestry coffee production is a good reference not only because it covers different indicators such as yield, carbon sequestration, canopy cooling effect, but also it is oriented for end-users (e.g., farmers, extension members) after simplifying the complexity to the more practical tool as a meta-model [115].

However, it is noteworthy that a series of limitations and bottlenecks exist with applying CSM, such as the requirement of a large number of variables, calibration for a new crop variety, and not a practical approach for unpredictable climate conditions. Furthermore, when it comes to yield prediction in developing countries, while many CGMs demand daily meteorological information as variables, only limited data are available in a small number of observations (e.g., weather stations) [116].

To tackle these difficulties, using satellite remote-sensing to combine with the CSMs is a well-known strategy to overcome some limitations of CSMs and narrow the gap between the predicted and measured yield by increasing the accuracy. Many scientific works have been reported on the integrated approach, such as APSIM [117], WOFOST [118], ORYZA [119]. Historically, this approach was proposed already in the 1970s [120,121]. Nowadays, a wide range of different assimilation methods of assimilation are present such as forcing, calibrating, and updating. The vegetative indices parameters (e.g., LAI) are often used for assimilation into the crop model.

Owing to the potential propagation of the uncertainty derived from satellite RS application, it is recommendable to use multi-objective variables to obtain more accurate simulation such as evapotranspiration and fraction of absorbed photosynthetically active radiation (FAPAR), according to Gumma et al. [122]. Another approach also has been developed recently on the basis of the fourdimensional variation algorithm (4DVar), considering the anisotropy of background error and time window to overcome the difficulty with certain irregular time intervals of observation and heterogeneous impacts of observations on the effect of yield simulation [123]. In the case of a non-linear model, which often occurs in CSM, various Kalman filter types have been used to estimate the uncertainty [124].

\section{Conclusion}

We conclude that the technical means of RS have expanded rapidly in agriculture over the last decades. The wide range of different agricultural themes using RS technologies (e.g., LULC, drought indices, and evapotranspiration) has been shown for the enhancement of field-based studies. However, our understanding of the physiological processes behind satellite observations has evolved at a somewhat slower pace. Thus, an important research gap between the actual state and desirable state of the knowledge exists in understanding the profound ecological meaning of remote observations. We believe that the application of RS technologies for adopting CSMs, which simulate a crop status over the seasons and predict the yield, represents an important contribution to understanding what we can observe from space. The aforementioned RS data and tools, including vegetation indices, drought indices, SAR data, and energy balance, are applicable for this combined approach. For example, rather than using NDVI solely for the understanding of the canopy status, integrating these indices within a crop model can speculate on other state variables, consequently serving a more holistic view for the sake of better understanding of crop and field status (e.g., soil moisture).

Multiple RS usages help us for field monitoring and support decision-making for field management. However, the availability of diverse data sources can be a double-edged sword: the first challenge is to synthesize many available data sources so that the end users' information is accurate and actionable. The acquisition of the ground-truth data is essential for this matter to crossvalidate the data from RS. To tackle this challenge, the integrated approach between RS and CSM can provide heterogeneous information across different phenological stages and estimate the uncertainty driven by RS data. Another option is creating a meta-model to simplify complex processes for other stakeholders (e.g., farmers, cooperative members, extension officers) who work in 
their field on a daily/weekly basis. The second challenge is technical concern about how such a large mass of data can be analyzed at a larger scale (e.g., global and regional scales). It requires the availability of data storage, computation capacity, and a suitable telecommunication environment. Fortunately, many recent tools such as Google Earth Engine freely provide access to pre-processed RS data and offer the possibility of conducting the computations on the cloud, thus greatly increasing the area and the complexity of the operations that can be carried out. The available data might make plans decisions, especially for end-users in developing countries who monitor their agricultural fields at farm, regional, and country levels.

\section{Acknowledgements}

Keiji Iindo wishes to acknowledge financial support (3710473400-1).

\section{Authors' contributions}

$\mathrm{KJ}, \mathrm{OK}, \mathrm{YW}, \mathrm{KI}, \mathrm{EA}$ and YEA wrote the manuscript; BM, FKE, YS and CK collaborated to the text redaction and formatted the whole text. All authors read and approved the final manuscript.

\section{Funding}

Not applicable.

\section{Availability of data and materials}

Not applicable.

\section{Declarations}

Ethics approval and consent to participate

For this type of study formal consent is not required.

\section{Consent for publication}

For this type of study formal consent is not required.

\section{Competing interests}

The authors declare that they have no competing interests.

\section{Author details}

${ }^{1}$ Agrosystems Research, Wageningen University \& Research, P.O. Box 16, 6700 AA Wageningen, The Netherlands. ${ }^{2}$ Center for Southeast Asian Studies, Kyoto University, Kyoto, Japan. ${ }^{3}$ Japan International Research Center for Agricultural Sciences (JIRCAS), Tsukuba, Japan. ${ }^{4}$ Colorado State University, Fort Collins, CO, USA. ${ }^{5}$ National Institute for Space Research (INPE), Av. dos Astronautas, 1758, São José dos Campos, SP CEP: 12.227-010, Brazil. '́ Japan Aerospace Exploration Agency (JAXA), Tsukuba, Japan.

\section{Received: 2 June 2021 Accepted: 4 September 2021}

Published online: 03 November 2021

\section{References}

1. Bhargava A. Climate change, demographic pressures and global sustainability. Econ Hum Biol. 2019;33:149-54. https://doi.org/10.1016/j. ehb.2019.02.007.

2. Kondratyev KY, Vassilyev $O B$, Grigoryev $A A$, Ivanian GA. An analysis of the Earth's Resources Satellite (ERTS-1) data. Remote Sens Environ. 1971;2:273-83.

3. Zhang K, Kimball J, Nemani R, et al. Vegetation greening and climate change promote multidecadal rises of global land evapotranspiration. Sci Rep. 2015;5:15956. https://doi.org/10.1038/srep1595610.1016/00344257(71)90100-3.

4. Sanyal J, Li XX. Application of remote sensing in flood management with special reference to monsoon asia: a review. Nat Hazard.
2004;33:283-301. https://doi.org/10.1023/B:NHAZ.0000037035.65105. 95.

5. Jiao W, Wang L, McCabe MF. Multi-sensor remote sensing for drought characterization: current status, opportunities and a roadmap for the future. Remote Sens Environ. 2021;256:112313. https://doi.org/10. 1016/j.rse.2021.112313.

6. Rahn E, Vaast P, Läderach P, van Aster P, Jassogne L, Ghazoul J. Exploring adaptation strategies of coffee production to climate change using a process-based model. Ecol Model. 2018;371:76-89. https://doi.org/10 1016/j.ecolmodel.2018.01.009.

7. MacDonald RB, Hall FG. Global crop forecasting. Science. 1980;208(16):4445. https://doi.org/10.1126/science.208.4445.670.

8. Barnet TL, Thompson DR. The use of large-area spectral data in wheat yield estimation. Remote Sens Environ. 1982;12:509-18. https://doi.org/ 10.1016/0034-4257(82)90025-6.

9. Thompson DR. Using Landsat digital data to detect moisture stress. Photogramm Eng Remote Sens. 1979;45:201-7.

10. Hariprasad P, Venkateswaran G, Niranjana SR. Diversity of cultivable rhizobacteria across tomato growing regions of Karnataka. Biol Control. 2014;72:9-16. https://doi.org/10.1016/j.biocontrol.2014.01.012.

11. Acker J, Williams R, Chiu L, Ardanuy P, Miller S, Schueler C, et al. Remote sensing from satellites. Ref Module Earth Syst Environ Sci. 2014. https:// doi.org/10.1016/B978-0-12-409548-9.09440-9.

12. Sampson PH, Zarco-Tejada P, Mohammed G, John R, Miller R, Noland T. Hyperspectral remote sensing of forest condition: estimating chlorophyll content in tolerant hardwoods. For Sci. 2003;49(3):381-91. https:// doi.org/10.1093/forestscience/49.3.381.

13. Teixeira AHDC, Bastiaanssen WGM, Ahmad MD, Bos MG. Reviewing SEBAL input parameters for assessing evapotranspiration and water productivity for the Low-Middle Sao Francisco River basin, Brazil: part A: calibration and validation. Agricult For Meteorol. 2009;149(34-2017):462-76. https://doi.org/10.1016/j.agrformet.2008.09.016.

14. Smith PM, Kalluri S, Prince SD, DeFries RS. The NOAA/NASA pathfinder AVHRR 8-Km land data set. Photogramm Eng Remote Sens. 1997:63:12-31.

15. Loverand TR, Merchant JW, Ohlen DO, Brown JF. Development of a land-cover characteristics database for the conterminous U.S. Photogrammetric Engineering and Remote Sensing 57(11):1453-1463.

16. Eva HD, Belward AS, De Miranda EE, Di Bella CM, Gond V, Huber $\mathrm{O}$, et al. A land cover map of South America. Glob Change Biol. 2004;10(5):731-44.

17. Friedl MA, Sulla-Menashe D, Tan B, Schneider A, Ramankutty N, Sibley $A$, et al. MODIS Collection 5 global land cover: algorithm refinements and characterization of new datasets. Remote Sens Environ. 2010;114(1):168-82.

18. McCloy KR. Development and evaluation of phenological change indices derived from time series of image data. Remote Sens. 2010;2(11):2442-73.

19. Aguiar DA, Rudorff BFT, Silva WF, Adami M, Mello MP. Remote sensing images in support of environmental protocol: monitoring the sugarcane harvest in São Paulo State, Brazil. Remote Sens. 2011;3(12):2682-703.

20. Adami M, Mello MP, Aguiar DA, Rudorff BFT, Souza AFD. A web platform development to perform thematic accuracy assessment of sugarcane mapping in South-Central Brazil. Remote Sens. 2012;4(10):3201-14.

21. Lunetta RS, Knight JF, Ediriwickrema J, Lyon JG, Worthy LD. Land-cover change detection using multi-temporal MODIS NDVI data. Remote Sens Environ. 2006;105(2):142-54.

22. Sterckx S, Benhadj I, Duhoux G, Livens S, Dierckx W, Goor E, et al. The PROBA-V mission: image processing and calibration. Int J Remote Sens. 2014;35(7):2565-88

23. Eberenz J, Verbesselt J, Herold M, Tsendbazar N-E, Sabatino G, Rivolta $G$. Evaluating the potential of PROBA-V satellite image time series for improving LC classification in Semi-Arid African Landscapes. Remote Sens. 2016;8(12):987.

24. Durgun Y, Gobin A, Van De Kerchove R, Tychon B. Crop area mapping using 100-m Proba-V time series. Remote Sens. 2016;8(7):585.

25. Arai E, Eyji Sano E, Dutra AC, Cassol HLG, Hoffmann TB, Shimabukuro YE. Vegetation fraction images derived from PROBA-V data for rapid assessment of annual croplands in Brazil. Remote Sens. 2020;12(7):1152. 
26. Hong HTC, Avtar R, Fujii M. Monitoring changes in land use and distribution of mangroves in the South Eastern part of the Mekong River Delta, Vietnam. Tropical Ecol. 2020;60(4):552-65.

27. Burke M, Lobell DB. Satellite-based assessment of yield variation and its determinants in smallholder African systems. Proc Natl Acad Sci USA. 2017;114(9):2189-94.

28. Wang L, D'Odorico P, Evans JP, Eldridge DJ, McCabe MF, Caylor KK, King EG. Dryland ecohydrology and climate change: critical issues and technical advances. Hydrol Earth Syst Sci. 2012;16:2585-603. https://doi.org/ 10.5194/hess-16-2585-2012.

29. lizumi T, Wagai R. Leveraging drought risk reduction for sustainable food, soil and climate via soil organic carbon sequestration. Sci Rep. 2019;9:19744. https://doi.org/10.1038/s41598-019-55835-y.

30. Cattivelli L, Rizza F, Badeck FW, Mazzucotelli E, Mastrangelo AM, Francia $E$, et al. Drought tolerance improvement in crop plants: an integrated view from breeding to genomics. Field Crop Res. 2008;105:1-14. https://doi.org/10.1016/j.fcr.2007.07.004.

31. Chenu K, Cooper M, Hammer GL, Mathews KL, Dreccer MF, Chapman SC. Environment characterization as an aid to wheat improvement: interpreting genotype-environment interactions by modelling waterdeficit patterns in North-Eastern Australia. J Exp Bot. 2011;62(6):174355. https://doi.org/10.1093/jxb/erq459.

32. Tuberosa R. Phenotyping for drought tolerance of crops in the genomics era. Front Physiol. 2012;3:1-26. https://doi.org/10.3389/fphys.2012. 00347.

33. Serraj R, Mcnally KL, Slamet-loedin I, Kohli A, Haefele SM, Atlin G, Kumar A. Drought resistance improvement in rice: an integrated genetic and resource management strategy. Plant Prod Sci. 2011;14(1):1-14.

34. Khan HR, Paull JG, Siddique KHM, Stoddard FL. Faba bean breeding for drought-affected environments: a physiological and agronomical perspective. Field Crop Res. 2010;115:279-86. https://doi.org/10.1016/j. fcr.2009.09.003.

35. Iseki K, Ikazaki K, Batieno JB. Cowpea yield variation in three dominant soil types in the Sudan Savanna of West Africa. Field Crop Res. 2021;261: 108012. https://doi.org/10.1016/j.fcr.2020.108012.

36. Shekhar A, Shapiro CA. What do meteorological indices tell us about a long-term tillage study? Soil Tillage Res. 2019;193:161-70. https://doi. org/10.1016/j.still.2019.06.004.

37. West H, Quinn N, Horswell M. Remote sensing for drought monitoring \& impact assessment: progress, past challenges and future opportunities. Remote Sens Environ. 2019;232: 111291. https://doi.org/10.1016/j. rse.2019.111291.

38. Jiao W, Wang L, McCabe MF. Multi-sensor remote sensing for drought characterization: current status, opportunities and a roadmap for the future. Remote Sens Environ. 2021;256: 112313. https://doi.org/10. 1016/j.rse.2021.112313.

39. Vicente-Serrano S, Cabello D, Tomás-Burguera M, Martín-Hernández $\mathrm{N}$, Beguería S, Azorin-Molina C, et al. Drought variability and land degradation in semiarid regions: assessment using remote sensing data and drought indices (1982-2011). Remote Sens. 2015;7(4):4391-423. https://doi.org/10.3390/rs70404391.

40. Delegido J, Verrelst J, Meza CM, Rivera JP, Alonso L, Moreno J. A rededge spectral index for remote sensing estimation of green LAl over agroecosystems. Eur J Agron. 2013;46:42-52. https://doi.org/10.1016/j. eja.2012.12.001

41. Kogan FN. Remote sensing of weather impacts on vegetation in nonhomogeneous areas. Int J Remote Sens. 2007;11(8):1405-19. https:// doi.org/10.1080/01431169008955102.

42. Sahoo RN, Dutta D, Khanna M, Kumar N, Bandyopadhyay SK. Drought assessment in the Dhar and Mewat Districts of India using meteorological, hydrological and remote-sensing derived indices. Nat Hazards 2015;77(2):733-51. https://doi.org/10.1007/s11069-015-1623-z.

43. Vicente-Serrano SM. Evaluating the impact of drought using remote sensing in a Mediterranean. Semi-arid Region Nat Hazards. 2007;40(1):173-208. https://doi.org/10.1007/s11069-006-0009-7.

44. Agutu NO, Awange JL, Zerihun A, Ndehedehe CE, Kuhn M, Fukuda Y. Assessing multi-satellite remote sensing, reanalysis, and land surface models' products in characterizing agricultural drought in East Africa. Remote Sens Environ. 2017;194:287-302. https://doi.org/10.1016/j.rse 2017.03.041.
45. Kogan FN. Application of vegetation index and brightness temperature for drought detection. Adw Space Res. 1995;15(11):91-100. https://doi. org/10.1016/0273-1177(95)00079-T.

46. Medrano $\mathrm{H}$. Regulation of photosynthesis of $\mathrm{C} 3$ plants in response to progressive drought: stomatal conductance as a reference parameter. Ann Bot. 2002;89(7):895-905. https://doi.org/10.1093/aob/mcf079.

47. Singh RP, Roy S, Kogan F. Vegetation and temperature condition indices from NOAA AVHRR data for drought monitoring over India. Int J Remote Sens. 2010;24(22):4393-402. https://doi.org/10.1080/01431 16031000084323

48. Seiler RA, Kogan F, Sullivan J. AVHRR-based vegetation and temperature condition indices for drought detection in Argentina. Adv Space Res. 1998:21(3):481-4. https://doi.org/10.1016/S0273-1177(97)00884-3.

49. Kukunuri ANJ, Murugan D, Singh D. Variance based fusion of $\mathrm{VCl}$ and TCI for efficient classification of agriculture drought using MODIS data. Geocarto Int. 2020. https://doi.org/10.1080/10106049.2020.1837256.

50. Wan Z, Wang P, Li X. Using MODIS Land surface temperature and normalized difference vegetation index products for monitoring drought in the southern Great Plains, USA. Int J Remote Sens. 2010;25(1):61-72.

51. Sandholt I, Rasmussen K, Andersen J. A simple interpretation of the surface temperature/vegetation index space for assessment of surface moisture status. Remote Sens Environ. 2002;79:213-24. https://doi.org/ 10.1016/S0034-4257(01)00274-7.

52. Patel NR, Parida BR, Venus V, Saha SK, Dadhwal VK. Analysis of agricultural drought using vegetation temperature condition index (VTCI) from Terra/MODIS satellite data. Environ Monit Assess. 2012;184(12):7153-63.

53. Wei W, Pang S, Wang X, Zhou L, Xie B, Zhou J, Li C. Temperature vegetation precipitation dryness index (TVPDI)-based dryness-wetness monitoring in China. Remote Sens Environ. 2020;248:11957. https://doi. org/10.1016/j.rse.2020.111957.

54. Liu L, Liao J, Chen X, Zhou G, Su Y, Xiang Z, Wang Z, Liu X, Li Y, Wu J, Xiong $X$, Shao $H$. The microwave temperature vegetation drought index (MTVDI) based on AMSR-E brightness temperatures for long-term drought assessment across China (2003-2010). Remote Sens Environ. 2017:199:302-20.

55. Miner GL, Bauerle WL, Baldocchi DD. Estimating the sensitivity of stomatal conductance to photosynthesis: a review. Plant Cell Environ. 2017;40:1214-38. https://doi.org/10.1111/pce.12871.

56. Zhang C, Filella I, Liu D, Ogaya R, Llusià J, Asensio D, Peñuelas J. Photochemical reflectance index (PRI) for detecting responses of diurnal and seasonal photosynthetic activity to experimental drought and warming in a Mediterranean shrubland. Remote Sens. 2017;9:1189. https://doi. org/10.3390/rs9111189.

57. Sun Y, Fu R, Dickinson R, Joiner J, Frankenberg C, Gu L, Xia Y, Fernando N. Drought onset mechanisms revealed by satellite solar-induced chlorophyll fluorescence: insights from two contrasting extreme events. J Geophys Res Biogeosci. 2015;120:2427-40. https://doi.org/10.1002/ 2015JG003150.

58. Boyd DS, Almond S, Dash J, Curran PJ, Hill RA. Phenology of vegetation in Southern England from Envisat MERIS terrestrial chlorophyll index (MTCI) data. Int J Remote Sens. 2011;32(23):8421-47.

59. Gao NDWI. A normalized difference water index for remote sensing of vegetation liquid water from space. Remote Sens Environ. 1996;58(3):257-66. https://doi.org/10.1016/S0034-4257(96)00067-3.

60. Jackson TJ, Chen D, Cosh M, Li F, Anderson M, Walthall C, Doriaswamy P, Hunt ER. Vegetation water content mapping using Landsat data derived normalized difference water index for corn and soybeans. Remote Sens Environ. 2004;92(4):475-82. https://doi.org/10.1016/j.rse. 2003.10.021.

61. GuY, Hunt E, Wardlow B, Basara JB, Brown JF, Verdin JP. Evaluation of MODIS NDVI and NDWI for vegetation drought monitoring using Oklahoma Mesonet soil moisture data. Geophys Res Lett. 2008;35(22). https://doi.org/10.1029/2008GL035772.

62. Gu Y, Brown JF, Verdin JP, Wardlow B. A five-year analysis of MODIS NDVI and NDWI for grassland drought assessment over the central Great Plains of the United States. Geogr Res Lett. 2007;34:L06407.

63. Orimoloye IR, Ololade OO, Mazinyo SP, Kalumba AM, Ekundayo OY, Busayo ET, Akinsanola AA, Nel W. Spatial assessment of drought severity in Cape Town area, South Africa. Heliyon. 2019;5(7):e02148. https://doi. org/10.1016/j.heliyon.2019.e02148. 
64. Erten E, Lopez-Sanchez JM, Yuzugullu O, Hajnsek I. Retrieval of agricultural crop height from space: a comparison of SAR techniques. Remote Sens Environ. 2016;187:130-44.

65. Cigna F, Bateson LB, Jordan CJ, Dashwood C. Simulating SAR geometric distortions and predicting Persistent Scatterer densities for ERS-1/2 and ENVISAT C-band SAR and InSAR applications: Nationwide feasibility assessment to monitor the landmass of Great Britain with SAR imagery. Remote Sens Environ. 2014;152:441-66. https://doi.org/10.1016/j.rse. 2014.06.025.

66. Prakash R, Singh D, Pathak NP. A fusion approach to retrieve soil moisture with SAR and optical data. IEEE J Sel Topics Appl Earth Observ Remote Sens. 2012;5:196-206. https://doi.org/10.1109/JSTARS.2011. 2169236.

67. Altese E, Bolognani O, Mancini M, Troch PA. Retrieving soil moisture over bare soil from ERS 1 synthetic aperture radar data: sensitivity analysis based on a theoretical surface scattering model and field data. Water Resour Res. 1996;32:653-61. https://doi.org/10.1029/95WR03638.

68. Wang L, Qu JJ. Satellite remote sensing applications for surface soil moisture monitoring: a review. Front Earth Sci China. 2009;3:237-47. https://doi.org/10.1007/s11707-009-0023-7.

69. Zribi M, Muddu S, Bousbih S, Al Bitar A, Tomer SK, Baghdadi N, Bandyopadhyay S. Analysis of L-Band SAR data for soil moisture estimations over agricultural areas in the tropics. Remote Sens. 2019;11:1122. https://doi.org/10.3390/rs11091122.

70. Chauhan S, Darvishzadeh R, Boschetti M, Nelson A. Estimation of crop angle of inclination for lodged wheat using multi-sensor SAR data. Remote Sens Environ. 2020;236:111488.

71. Stroppiana D, Boschetti M, Azar R, Barbieri M, Collivignarelli F, Gatti $L$, Fontanelli G, Busseto L, Holez F. In-season early mapping of rice area and flooding dynamics from optical and SAR satellite data. Eur J Remote Sens. 2019;52(1):206-20. https://doi.org/10.1080/22797254. 2019.1581583.

72. Saradjian MR, Hosseini M. Soil moisture estimation by using multipolarization SAR image. Adv Space Res. 2011;48(2):278-86. https://doi.org/10. 1016/j.asr.2011.03.029.

73. Mirsoleimani HR, Sahebi MR, Baghdadi N, El Hajj M. Bare soil surface moisture retrieval from sentinel-1 SAR data based on the calibrated IEM and Dubois models using neural networks. Sensors. 2019;19(14):3209. https://doi.org/10.3390/s19143209.

74. Das K, Paul PK, Dobesova Z. Present status of soil moisture estimation by microwave remote sensing. Cogent Geosci. 2015;1(1):1-21. https:// doi.org/10.1080/23312041.2015.1084669.

75. Jonard F, Bircher S, Demontoux F, Weihermüller L, Razafindratsima S, Wigneron JP, Vereecken $\mathrm{H}$. Passive L-band microwave remote sensing of organic soil surface layers: a tower-based experiment. Remote Sens. 2018;10(2):304. https://doi.org/10.3390/rs10020304.

76. Zribi M, Gorrab A, Baghdadi N, Lili-Chabaane Z, Mougenot B. Influence of radar frequency on the relationship between bare surface soil moisture vertical profile and radar backscatter. IEEE Geosci Remote Sens Lett. 2014;11(4):848-52. https://doi.org/10.1109/LGRS.2013.2279893.

77. Jagdhuber T, Hajnsek I, Bronstert A, Papathanassiou KP. Soil moisture estimation under low vegetation cover using a multi-angular polarimetric decomposition. IEEE Trans Geosci Remote Sens. 2013;51(4):2201-15.

78. Vereecken $\mathrm{H}$, Huisman JA, Pachepsky Y, Montzka C, van der Kruk J, Bogena H, Weihermüller L, Herbst M, Martinez G, Vanderbourght J. On the spatio-temporal dynamics of soil moisture at the field scale. J Hydrol. 2014;516:76-96. https://doi.org/10.1016/j.jhydrol.2013.11.061.

79. Western AW, Zhou S-L, Grayson RB, McMahon TA, Blöschl G, Wilson DJ. Spatial correlation of soil moisture in small catchments and its relationship to dominant spatial hydrological processes. J Hydrol. 2004;286(14):113-34. https://doi.org/10.1016/j.jhydrol.2003.09.014.

80. Avtar R, Suzuki R, Takeuchi W, Sawada H. PALSAR 50 m mosaic data based national level biomass estimation in Cambodia for implementation of REDD+ mechanism. PLoS ONE. 2013;8(10): e74807. https://doi. org/10.1371/journal.pone.0074807.

81. Gao S, Liu X, Bo Y, Shi Z, Zhou H. Rubber identification based on blended high spatio-temporal resolution optical remote sensing data: a case study in Xishuangbanna. Remote Sens. 2019;11(5):496. https://doi. org/10.3390/rs11050496.
82. Trisasongko BH. Mapping stand age of rubber plantation using ALOS-2 polarimetric SAR data. Eur J Remote Sens. 2017;50(1):64-76.

83. Brinkhoff J, Vardanega J, Robson AJ. Land cover classification of nine perennial crops using sentinel- 1 and -2 data. Remote Sens. 2019;12(1):96.

84. Santoso $H$, Tani $H$, Wang X. A simple method for detection and counting of oil palm trees using high-resolution multispectral satellite imagery. Int J Remote Sens. 2016;37(21):5122-34. https://doi.org/10. 1080/01431161.2016.1226527.

85. Douxchamps S, Van Wijk MT, Silvestri S, Moussa AS, Quiros C, Ndour NYB, et al. Linking agricultural adaptation strategies, food security and vulnerability: evidence from West Africa. Reg Environ Change. 2015;16(5):1305-17. https://doi.org/10.1007/s10113-015-0838-6.

86. Mizuno K, Fujita MS, Kawai S. Catastrophe \& Regeneration in Indonesia's Peatlands: Ecology, Economy \& Society. In: Mizuno K, Fujita MS, Kawai S, editors. NUS Press, Singapore, 2016.

87. Avtar R, Takeuchi W, Sawada H. Monitoring of biophysical parameters of cashew plants in Cambodia using ALOS/PALSAR data. Environ Monit Assess. 2013;185(2):2023-37. https://doi.org/10.1007/ s10661-012-2685-y.

88. Bai J, Cui Q, Zhang W, Meng L. An approach for downscaling SMAP soil moisture by combining Sentinel-1 SAR and MODIS data. Remote Sens. 2019;11(23):2736. https://doi.org/10.3390/rs11232736.

89. Forkuor G, Conrad C, Thiel M, Ullmann T, Zoungrana E. Integration of optical and synthetic aperture radar imagery for improving crop mapping in Northwestern Benin. West Africa Remote Sens. 2014;6(7):647299. https://doi.org/10.3390/rs6076472.

90. Numbisi FN, Van Coillie FMB, De Wulf R. Delineation of cocoa agroforests using multiseason Sentinel-1 SAR Images: a low grey level range reduces uncertainties in GLCM texture-based mapping. ISPRS Int J Geo-Inform. 2019:8(4):179. https://doi.org/10.3390/ijgi8040179.

91. Seiler C, Moene AF. Estimating actual evapotranspiration from satellite and meteorological data in Central Bolivia. Earth Interact. 2011;15(12):1-24. https://doi.org/10.1175/2010El332.1.

92. Bastiaanssen WGM, Pelgrum H, Wang J, Ma Y, Moreno JF, Roerink GJ, van der Wal T. A remote sensing surface energy balance algorithm for land (SEBAL):: Part 2: Validation. J Hydrol. 1998;213-229:213. https://doi.org/ 10.1016/S0022-1694(98)00254-6.

93. Jassas H, Kanoua W, Merkel B. Actual evapotranspiration in the Al-Khazir Gomal Basin (Northern Iraq) using the surface energy balance algorithm for land (SEBAL) and water balance. Geosciences. 2015;5(2):14159. https://doi.org/10.3390/geosciences5020141.

94. Bala A, Rawat KS, Misra AK, Srivastava A. Assessment and validation of evapotranspiration using SEBAL algorithm and Lysimeter data of IARI agricultural farm, India. Geocarto Int. 2015;31(7):739-64. https://doi.org/ 10.1080/10106049.2015.1076062.

95. Zwart SJ, Bastiaanssen WGM. SEBAL for detecting spatial variation of water productivity and scope for improvement in eight irrigated wheat systems. Agric Water Manag. 2007;89(3):287-96. https://doi.org/10. 1016/j.agwat.2007.02.002

96. Cai X, Sharma BR, Matin MA, Sharma D, Gunasinghe S. An assessment of crop water productivity in the Indus and Ganges River Basins: current status and scope for improvement. Colombo, Sri Lanka: International Water Management Institute (IWMI). (IWMI Research Report 140). p. 22. 2010. https://doi.org/10.5337/2010.232.

97. Lopo M, Teixeira dos Santos CA, Páscoa RNMJ, Graça AR, Lopes JA. Near infrared spectroscopy as a tool for intensive mapping of vineyards soil. Precis Agricult. 2017;19(3):445-62. https://doi.org/10.1007/ s11119-017-9529-2.

98. Bashir MA, Hata T, Tanakamaru H, Abdelhadi AW, Tada A. Satellitebased energy balance model to estimate seasonal evapotranspiration for irrigated sorghum: a case study from the Gezira scheme, Sudan. Hydrol Earth Syst Sci. 2008;12:1129-39. https://doi.org/10.5194/ hess-12-1129-2008.

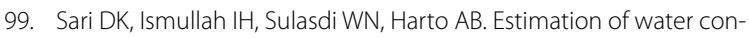
sumption of lowland rice in tropical area based on heterogeneous cropping calendar using remote sensing technology. Procedia Environ Sci. 2013;17:298-307. https://doi.org/10.1016/j.proenv.2013.02.042.

100. Yang Y, Shang S, Jiang L. Remote sensing temporal and spatial patterns of evapotranspiration and the responses to water management 
in a large irrigation district of North China. Agric For Meteorol. 2012;164:112-22. https://doi.org/10.1016/j.agrformet.2012.05.011Get.

101. Mhawej M, Faour G. Open-source Google Earth Engine 30-m evapotranspiration rates retrieval: the SEBALIGEE system. Environ Model Softw. 2020;133:104845. https://doi.org/10.1016/j.envsoft.2020.104845.

102. Zhang K, Kimball JS, Running SW. A review of remote sensing based actual evapotranspiration estimation. WIREs Water. 2016. https://doi. org/10.1002/wat2.1168.

103. Zeng ZZ, Piao SL, Lin X, Yin GD, Peng SS, Ciais P, Myneni RB. Global evapotranspiration over the past three decades: estimation based on the water balance equation combined with empirical models. Environ Res Lett. 2012;7: 014026. https://doi.org/10.1088/1748-9326/7/1/ 014026.

104. Ryu Y, Baldocchi DD, Kobayashi H, van Ingen C, Li J, Black TA, Beringer J, van Gorsel E, Knohl A, Law BE, Roupsard O. Integration of MODIS land and atmosphere products with a coupled-process model to estimate gross primary productivity and evapotranspiration from $1 \mathrm{~km}$ to global scales. Global Biogeochem Cycles. 2011;25:4017. https://doi.org/10. 1029/2011GB004053.

105. Silva COF, Teixeira AHC, Manzione RL. Agriwater: an R package for spatial modelling of energy balance and actual evapotranspiration using satellite images and agrometeorological data. Environ Model Softw. 2019;120:104497. https://doi.org/10.1016/j.envsoft.2019.104497.

106. Allam M, Mhawej Q, Meng G, Faour Y, Abunnasr A, Xinli FH. Monthly 10-m evapotranspiration rates retrieved by SEBALI with Sentinel-2 and MODIS LST data. Agric Water Manag. 2021;243:106432. https://doi.org/ 10.1016/j.agwat.2020.106432.

107. Nyolei D, Nsaali M, Minaya V, van Griensven A, Mbilinyi B, Diels J, Hessels $J$, Kahimba F. High resolution mapping of agricultural water productivity using SEBAL in a cultivated African Catchment, Tanzania. Phys Chem Earth. 2019;112:36-49. https://doi.org/10.1016/.pce.2019.03.009.

108. Dias SHB, Filgueiras R, Fernandes Filho El, Arcanjo GS, Silva GHD, Mantovani EC. Reference evapotranspiration of Brazil modeled with machine learning techniques and remote sensing. PLOS ONE. 2021;16(2):e0245834. https://doi.org/10.1371/journal.pone.0245834

109. Prakash Mohan MM, Rajitha K, Varma MRR. Integration of soil moisture as an auxiliary parameter for the anchor pixel selection process in SEBAL using Landsat 8 and Sentinel-1A images. Int J Remote Sens. 2020;41(3):1214-31. https://doi.org/10.1080/01431161.2019.1658239.

110. de Wit CT. Photosynthesis of Leaf Canopies. Agricultural Research Report 1965. No. 663. PUDOC, Wageningen.

111. Monteith JL. Light distribution and photosynthesis in field crops. Ann Botany. 1965;29:17-37. https://doi.org/10.1093/oxfordjournals.aob. a083934.

112. Duncan WG, Loomis RS, Williams WA, Hanau R. A model for simulating photosynthesis in plant communities. Hilgardia. 1967;38:181-205.

113. DeWit CT. Simulation of assimilation, respiration and transpiration of crops. New York: Wiley; 1978.
114. Duncan WG. Leaf angles, leaf area, and canopy photosynthesis. Crop Sci. 1971;11:482-5.

115. Vezy R, LeMaire G, Christina M, Georgiou S, Imbach P, Hidalgo HG, et al. DynACof: a process-based model to study growth, yield and ecosystem services of coffee agroforestry systems. Environ Modell Softw. 2020;124:104609. https://doi.org/10.1016/j.envsoft.2019.104609.

116. Steinbuch L, Brus DJ, Brussel LGV, Heuvelink GBM. Geostatistical interpolation and aggregation of crop growth model outputs. Eur J Agron. 2016:77:111-21. https://doi.org/10.1016/j.eja.2016.03.007.

117. Feng P, Wang B, Liu DL, Waters C, Xiao D, Shi L, Yu Q. Dynamic wheat yield forecasts are improved by a hybrid approach using a biophysical model and machine learning technique. Agricult For Meteorol. 2020;2020(107922):285-6. https://doi.org/10.1016/j.agrformet.2020. 107922.

118. Bai T, Wang S, Meng W, Zhang N, Wang T, Chen Y, Mercatoris B. Assimilation of remotely-sensed LAl into WOFOST model with the SUBPLEX algorithm for improving the field-scale jujube yield forecasts. Remote Sens. 2019;11(16):1945. https://doi.org/10.3390/rs11161945.

119. Setiyono TD, Quicho ED, Gatti L, Campos-Taberner M, Busetto L, Collivignarelli F, García-Haro FJ, Boschetti M, Khan NI, Holecz F. Spatial rice yield estimation based on MODIS and sentinel-1 SAR data and ORYZA crop growth model. Remote Sens. 2018;10(2):293. https://doi.org/10. 3390/rs10020293.

120. Arkin GF, Wiegand $\mathrm{CL}$, Huddleston $\mathrm{H}$. The future role of a crop model in large area yield estimation. In: Proceedings of the Crop Modeling Workshop, 1977;87-116. USDA-NOAA-EDIS-CEAS, Columbia, MO, USA.

121. Wiegand CL, Richardson AJ, Kanemasu ET. Leaf area index estimates for wheat from landsat and their implications for evapotranspiration and crop modeling. Agron J. 1979;71:336-42. https://doi.org/10.2134/agron j1979.00021962007100020027x.

122. Gumma MK, Kadiyala MDM, Panjala P et al. Assimilation of remote sensing data into crop growth model for yield estimation: a case study from India. J Indian Soc Remote Sens. 2021. https://doi.org/10.1007/ s12524-021-01341-6.

123. Wu S, Yang P, Chen Z, Ren J, Li H, Sun L. Estimating winter wheat yield by assimilation of remote sensing data with a four-dimensional variation algorithm considering anisotropic background error and time window. Agric For Meteorol. 2021;301: 108345. https://doi.org/10. 1016/j.agrformet.2021.108345.

124. Pan $\mathrm{H}$, Chen Z, de Wit A, Ren J. Joint assimilation of leaf area index and soil moisture from sentinel- 1 and sentinel-2 data into the WOFOST model for winter wheat yield estimation. Sensors. 2019;19(14):3161 . https://doi.org/10.3390/s19143161.

\section{Publisher's Note}

Springer Nature remains neutral with regard to jurisdictional claims in published maps and institutional affiliations.

\section{Submit your manuscript to a SpringerOpen ${ }^{\circ}$ journal and benefit from:}

- Convenient online submission

- Rigorous peer review

- Open access: articles freely available online

- High visibility within the field

- Retaining the copyright to your article

Submit your next manuscript at $\boldsymbol{\nabla}$ springeropen.com 